Postprint Version 1.0

Journal website http://dx.doi.org

Pubmed link http://www.ncbi.nlm.nih.gov/entrez/query.fcgi?db=pubmed\&cmd=Retrieve\&dop

DOI $\mathrm{t}=$ Abstract\&list uids=11390152\&query $\mathrm{hl}=18$ \&itool=pubmed docsum 10.1016/S0738-3991(01)00097-0

\title{
Patient education in The Netherlands
}

\author{
JOZIEN M. BENSING ${ }^{\text {A, }}$, ADRIAAN VISSER ${ }^{\text {B }}$, HANS SAAN ${ }^{\mathrm{C}}$ \\ a Department of Health Psychology, Netherlands Institute of Primary Care (NIVEL), University of \\ Utrecht, P.O. Box 1568, 3500 BN Utrecht, The Netherlands \\ b Helen Dowling Institute for Biopsychosocial Medicine, Utrecht, The Netherlands \\ c National Institute for Health Promotion, Woerden, The Netherlands \\ * Corresponding author. Tel.: +31-30-27-29-666; fax: +31-30-27-29-729. E-mail address: \\ j.bensing@nivel.nl (J.M. Bensing).
}

\begin{abstract}
This article presents the development of patient education (PE) in The Netherlands from a historical perspective. A description is given of the first pioneering years from the 70 s till the late 80s, in which early topics like the organization of $\mathrm{PE}$, the orchestration of $\mathrm{PE}$ between different disciplines, the role of the social environment, the provision of PE in difficult patient groups and - most of all - the technical development of educational materials took the time and attention of the growing group of professionals that were engaged in patient education. Recent developments concern the legal aspects of PE, national policy, the role of health insurance, the position of patient organizations and the development of patient education in specific professional groups, e.g. general practitioners, nurses, physiotherapists, pharmacists, and dentists. There is no doubt that patient education has been professionalized considerably during the last decades. Nevertheless, new issues emerge and some old issues still need to be solved. The effective use of information material, the need for counseling as part of PE, and the relevance of coordination of care are longtime, but still actual problems in PE. More recent issues are the pressures on PE because of capacity restraints, the influence of the media and perhaps most of all: the apparent need for a patient-centered attitude and a more two-sided way of communication. Finally, the future policy topics in the Dutch patient education are discussed.
\end{abstract}

\section{INTRODUCTION}

In the last 30 years, Dutch patient education has been strongly developed in hospitals as well as in primary health care. After pioneering years since the beginning of the 70s, the implementation of patient education has been gradually incorporated in several health care professions. Patient education is now an integrated and well accepted part of the communication in health care [1]. During the years, several issues were emerged, both in the structure and process and content of patient education. Some of these issues have been solved quite well, others have proven to be quite stubborn. Besides, changing conditions in health care system, and advancing insights in the efficacy and effectiveness of patient education have raised several new challenges that need be addressed in the future. 


\section{PIONEERING YEARS OF PATIENT EDUCATION}

Since the beginning of the 70s, patient education (PE) has received a modest, but steady stream of attention from health policy makers as well as health care providers and researchers. The need for systematic patient education was firstly felt in the hospital world. Studies in the US and the UK showed effects of PE on the length of stay in hospitals, reducing the health care costs. Later on cultural changes (including patient empowerment), rapid developments in health care technology, and the growing differentiation among medical specialists influenced the need of PE [2].

In contrast, a lot of satisfaction studies showed that many patients were not satisfied with the quality of PE; they did not grasp what was happening to them, and were beginning to ask for more information on their illness, treatment and prognosis $[3,4]$. This gave an impetus to the professionalization of patient education. Till then, patient education was not acknowledged as a separate discipline. Awareness of teaching techniques was completely lacking. The doctor decided without much reflection which information patients should get about their medical condition, the prognosis, and the most adequate treatment. At that time, openness about serious and life-threatening diseases (like cancer) was not the general habit.

In the wake of the turbulent days of Paris 1968 (which spread its influence throughout Europe), a growing amount of health care professionals, policy makers and initial patient groups began to express new opinions on patients' right to be fully informed about their diseases. This required specific communication skills, with which most health care professionals were not familiar. At the beginning of the 70s, the first courses in communication skills were developed within medical faculties [3]. Around the same time the first experiments with patient education were launched and the first educational materials developed [5].

\section{EARLY ISSUES AND SOLUTIONS}

Early topics in patient education were: (1) the organization of PE, institutional policy on the development of leaflets, and videos; (2) the "orchestration"' (tuning of patient education among different disciplines); (3) the role of the social environment, the presence of family-members, especially in the treatment of children; (4) individual competence (e.g. in having bad-news conversations); (5) coping with certain patient categories (aggressive or impertinent patients; older patients; gender issues).

The typical Dutch solution was the introduction in hospitals of a special coordinator for patient education, who was responsible for the organization of PE, the development of new materials, and the enhancement of the skills and motivation of the health care professionals [6]. Moreover, in most hospitals specialized nurses and patient educators were recruited as focal persons at the admission departments. Much effort was given to the development of new patient-oriented educational materials. These were in most cases organizational and technological solutions. The coordination within hospitals got strong priority. There was not much exchange of expertize and experiences between the projects: "all flowers were allowed to blossom"' [7]. Dissemination of knowledge to other health care professionals, like general practitioners was slow, although patient education became part of the formal task-profile of general practitioners, and in its slipstream of the GP-curriculum in the mid-80s [8].

Several developments stimulated the exchange of experiences in PE: the Dutch Society for Patients was founded and-right from the start—put 'the need for information' high on its agenda. As support for the health care professionals, the National Center for Health Promotion was founded to coordinated projects and provide information on PE. Also the start of Faculties of Health Education, with a curriculum in patient education was an important condition in the early development of PE. Since the late 80s, PE is incorporated in the curriculum of most allied health professionals: GP's [9]; dentists [10]; hospital doctors [11] and nurses [12]. In the meantime, the Ministry of Health showed its interest in patient education by financing local initiatives, stimulating PE-efforts in public health, and by supporting general and categorical patient organizations. At the national level, patient education got a firm position in several policy papers aimed at the strengthening of patients' position in health care. After the Structuurnota Gezondheidszorg (1974) which was the first to mention patients' rights in health care, several white papers on “'patient policy”' were published (1981, 1983, 1988 and 1989). By 
the end of the 80s, patient education was firmly placed on the agenda. PE became a factor in the market of health care [13].

\section{THE IMPLEMENTATION OF PE IN HEALTH CARE}

\subsection{Legal aspects of $P E$}

In the late $80 \mathrm{~s}$ and the $90 \mathrm{~s}$, the position of PE in the health care system was further formalized. In the white " paper on quality of care" (1990), much attention was given to patients' influence on health care in general. Along with patients" "right-to-speak" (regulating patients democratic rights and handling of formal complaints in health care), patients "right-to- know" was formulated and supported by the development of patient-information systems and a series of so-called "patient laws". For PE, the most far-reaching law was the "act on the medical treatment agreement" (WGBO), that came into effect in 1995. In this law, patients' right is established to receive all information that is necessary to give an "informed consent" on all diagnostic, therapeutic and research procedures. As a result of this law, a flood of standardized educational materials were developed for the most common diseases and medical interventions. All hospitals and every general practice now has display cases with numerous leaflets in its waiting room; often accompanied by running videos and other informational gadgets.

A second major impulse has been the introduction of legislation on quality systems in health care organizations. Under this law health care organizations were obliged to involve patients in their systems of quality assurance. Specific criteria were elaborated by patient organizations, among which 'information giving' took a prominent place in most occasions. While patients are in general very satisfied with the quality of delivered care, lack of adequate information is one of the most common complaints in systematic patient satisfaction surveys. This made the management of health care organizations very much aware of the need to professionalize PE and relate it to customer involvement.

\subsection{National support}

In Dutch policy, health care providers themselves are supposed to take responsibility for patient education, while the government adopts a supporting policy towards the implementation of PE. Largely financed by the Ministry of Health, the Netherlands Institute for Health Promotion and Education (NIGZ) was assigned to support all kinds of patient education activities. The institute published a journal and a series of books on PE for several target groups, for instance: nurses in hospitals and in home care; pharmacists; allied professionals; psychiatrists; professionals in urgent care; diabetic; surgical and cancer patients [14].

Furthermore, the NIGZ got a formal task in supporting and coordinating research projects in hospitals and primary health care. A handbook on the role and responsibilities of the PE coordinator was produced that helped to integrate patient education in hospital care. Also a book on the state of the art of health promotion and patient education has been published [15].

\subsection{General practice}

Consistent with the distribution of responsibilities in the Dutch health care system, all kind of PE activities were initiated by professional organizations. The Netherlands Academy of General Practitioners (NHG), who is responsible for the development of the so-called "standards on good quality of care'” in general practice, has developed the habit of devoting a paragraph on PE in each new standard that is published. In this PE paragraph, guidelines are presented about how patients should be informed about the etiology and the prognosis of their illness, and about the most adequate treatment [16]. Advises about lifestyle and coping with illness are also often incorporated. In this way, $\mathrm{PE}$ has become a regular part of GP-care [3]. At present, a selection of PE material for inclusion in the GP desktop computer is prepared. Even personalized print-outs can be provided.

\subsection{Nurses}

Nurses often were a stimulating factor in the development of PE, because nurses are daily confronted with the information needs of patients. Some nurses took the initiative to develop patient activities in hospitals. Also specialized nurses extended their role in PE. Good examples are diabetes nurses and 
psychosocial cancer nurses. Several studies confirmed their beneficial role for patients. Nurses are able to fulfill an important role in PE; the threshold in the communication with patients is low [12].

\subsection{Dentists}

Dentistry was rather early in adopting education in their package [10]. Mainly the tasks were delegated to dental hygienists who applied teaching interventions both in treatment and in public programmes. The "ivory cross" acted as a source of educational material and was in collaboration with universities instrumental in evaluation and feedback. For anxious patients special programs for counseling and education were developed.

\subsection{Physiotherapists}

More recently, physiotherapists recognized the relevance of PE. The trigger was given by the disappointing results from MTA-research on physiotherapy. The evidence-base of applied treatments was rather meagre in most research projects. But many professionals in the field argued, that this was due to the low compliance of their patients. As home-exercising is an important element in this type of treatment, it is very important that patients know and understand what they have to do, and get the motivation to sustain these exercises. At this point, PE comes as an important factor [17].

\subsection{Pharmacies}

At the same time, PE was acknowledged as a relevant task in pharmacies. In 1994, the Royal Netherlands Association of Pharmacists (KNMP) established a working party on communication in the pharmacy. This was part of a general tendency to change the role-profile of the pharmacist from a deliverer of medicines into a health care provider who is responsible for information and advice. The NIGZ has developed a self-diagnostic instrument with which pharmacists can assess themselves on these educational tasks. As in other health care organizations, the link with quality systems is used as a stimulant.

\subsection{Health insurance}

Health insurance organizations (Dutch sickfunds) became a strong regulating factor in the health care by means of controlling the budgets. This was leading to a growing interest in factors influencing the use of health care. PE is applied to influence the adequate use of health care provisions and the awareness of costs. Also attention has been paid to primary health prevention by means of a national magazine. Furthermore, research projects on the role of PE in the application of new technologies like CD-ROMs have been financially supported by health insurance organizations.

\subsection{Patient organizations}

However, the strongest impetus for the systematic implementation of PE in the Dutch health care system has undoubtly come from general and categorical patient organizations. Since the so-called "Leidschendamconferenties" (a series of conferences in which all Dutch policy makers in health care made agreements about the implementation of quality systems in health care), patient organizations have been looked upon as the third relevant actor (besides health care providers and health insurance companies). Empowered and financially supported by the national government, patient organizations are developing growing influence. One of the main activities of these patient organizations is providing information to their members. Much information, advice and support is also exchanged in self-care groups. This is partly information that stems from own experiences (the term "experienceexpert" has been given to the typical advice-role of fellow-patients), but the more advanced patient organizations also provide medical information from medical sources. Some even employ medical doctors for that purpose. It is remarkable that how well these patient organizations are in the use of new media, like Internet. The national government supports a national platform for patient organizations, including a journal and regional offices for patient complaints. A special group are the categorical patient organizations that are backed up by strong national organizations, e.g. Heart or CARA Foundation. They combine roles of linking persons, fund raising and local advocates.

\section{PROBLEMS TO SOLVE}

The pioneering days of PE are definitely over. PE is now acknowledged as an essential part of health care. The overall change in morbidity from acute to chronic diseases, which all ask for changes in lifestyle and a lifelong adjustment to illness (including the intake of medicine and the necessity of 
exercising) has made clear that doctors can and should not any longer take the responsibility for patients' health alone. Patient rights (embedded in legislature) go hand in hand with the view that patients themselves must take responsibility for their health. As a consequence, health care providers have an important role in informing and advising patients on the most adequate way to maintain the best health possible. Patient education is the tool to reach these relatively new aims in health care. However, these developments do not mean that everything is clear, nor that all PE is a success. There are still many problems to solve.

\subsection{Effective use of information material}

We have learned quite well to develop all kind of informational material, like leaflets, videos, selfcare books, etc. but in effect studies, the results of this type of PE are often a bit disappointing. One of the reasons might be that too much is expected from a too simple intervention. Another reason is that this information is not tuned to the individual circumstances, preferences and needs of the patients to whom it is directed. Slowly a differentiation of materials to fit to stages in the patients career is being applied. Patients can be very different in their informational needs. In order to reach the educational aims, information material should be better tuned to patients' characteristics. One way of doing this is to provide information in a face-to-face consultation in which the needs, preferences and individual wishes can be established in a two-sided way of communication. Health care providers should be aware of the fact that educational material may support patient education, but can never replace it. Taking home audio- or videotaped consultations may strengthen the individualized education. Another way to individualize the information can be based on patients' risk profiles and other characteristics. In this way, one can provide very efficient, Taylor-made information. This is successfully applied in The Netherlands in a campaign on anti-smoking and fat intake, in which the target groups were provided with individualized educational letters. These examples of public health activities may be applied to patient education in hospitals (e.g. tuning the information at the age of patients, their condition, and received therapy). In general, new technology like hyperlinks is seen to be able to adapt education more closely to the users need.

\subsection{Need for counseling}

Another problem in PE is that it is never performed in a neutral situation. Health problems are often laden with emotions. From psychology, it is known that emotions block the reception and retention of relevant information. The shock of a bad-news message, but also the relief when nothing serious has been found, both result in an emotional status that prevents the patient from hearing what the doctors tell them (regardless the effort doctors take to provide technically correct and patient-oriented information). Patients mention this issue as one of the main communication problems in health care: doctors are giving them all kind of medical-technical information, while they are still in need of emotional support and understanding. As George Engel (the American founder of the biopsychosocial model in medicine) once poetically said: "patients always have a double need: the need to know and understand, but also, and perhaps even more important: the need to feel known and understood"'. Patient education is often one-side directed to this first need of the patient (the cognitive need), thereby neglecting the second need (which is an emotional need). When PE misses its aim, it is often by this universal phenomenon. The need for more attention to counseling in patient education strongly applies to the chronically ill patients.

\subsection{Coordination of care}

A third problem has to do with role division and organization of PE within health care. Chronic patients have to cope with a lot of health care providers: GPs, medical specialists, nurses, physiotherapists, pharmacists, dieticians, and sometimes also psychosocial health care providers. Continuity of care has become a serious problem in health care and continuity of education is still neglected. PE is often limited by so called "boundary fights": who is responsible for which part of the education? Blaming others is sometimes an easy way out for a complicated task like PE. However, PE is very important in the continuity and the integrating of the health care. PE is not only necessary due the growing fragmentation of the care, but is also a crucial condition in the follow-up of treatments.

\subsection{New challenges}

Earlier, we noted that emancipatory processed shifted the power balance between patients and professionals. Patients tend to see themselves at least co-responsible for their health. Development of 
genetechnology may again shift this picture. Chances and risks for health are determined also by luck or accident. How will people be able to respond to this type of information. Will professionals be able to maintain in their PE a balance between the blind forces of nature and personal responses to the challenges. Especially, the counseling of young couples considering parenthood may develop into a sensitive area where issues of risk-management and ethics meet [18].

\subsection{Capacity restraints}

Education is a process with two parties involved. In the early stages, brochures were often seen to replace the personal exchange and to be a more cost-efficient way to handle the "information giving". Now, the focus has changed to real education and to both patient behavior and satisfaction as outcomes. Now "information- exchange"' and learning requires more of the time of professionals. However, this insight occurs at a time where time constraints are evident, both because of cost-control operations and a general labor shortage in health care. In a context where waiting lists and a shortage of adequate staff is common, the capacity to apply state-of-the-art patient education may be threatened. Common is the trend to try to delegate these tasks. GP's often put the responsibility on their assistants, medical specialists on hospital nurses, without providing adequate educational training. At the same time, professionals tend to forget that things said in a hurry without adequate educational care, may have an adverse impact on the patient that cannot be corrected by delegated tasks. Social changes have been said to be more difficult then surgery, but this notion is not yet being reflected in the allocation of resources in health care.

\subsection{The influence of the media}

The last, but not the least issue that deserves attention is the influence of the media. Newspapers, magazines, radio and television pay a lot of attention to health care issues. Many times this is done in a very professional and adequate way. However, there are also examples of the influence of pharmaceutical industry on the content of the programs and articles. For instance, when a new type of drug is plugged, or a new, very expensive and still experimental surgery is demonstrated. In a broader sense, these public informational sources provide the patient with all kind of information that can counteract the doctors' policy. In The Netherlands, GPs have the explicit philosophy to be parsimonious in their medical interventions. This professional attitude has not only to do with costs, but also and especially with the potential harms of superfluous interventions (side-effects of medicines, surgery- risks, hospital infections, antibiotic-resistance). While the media influence can be regarded as a way of empowerment to the patient, the risk is that the doctor gets stuck between the patient and the media. PE then becomes a negotiating process, for which the doctor often is not well equipped.

Help desks that can be approached by telephone very often are well checked: they use professional consultants to control the quality of the information provided. Internet takes a special position in this issue, because it is an opportunity as well as a danger in PE. It is an opportunity, because it makes all kind of medical information directly accessible to patients who want to know more. But is also a danger, because there is no quality control on the contents of this information. There is certainly a need for quality controlling "editors" on the Internet, or for certain types of formally acknowledged "quality hallmark" for which information providers may apply. Another approach is that the owner of the website is perceived to have a trustworthy status. The "net doctor" on behalf of the Royal Dutch Medical Society developed by the NIGZ shows this. In 4 months, it was visited 1000000 times. The wide availability of video has enhanced training for patient education. The NIGZ has produced a package " video on the job" to help professionals to analyze their patient interactions and improve their educational interventions.

\section{CONCLUSION: FUTURE POLICY TOPICS}

In comparison with other European countries, the Dutch patient education reached a high quality due to a close cooperation between the national government, patient organizations and applied research projects in hospitals and primary health care. However, there are several topics in Dutch PE that still needs further attention in the health care policy.

1. The need for Taylor-made information for patients (personal informational letters, feedback by tapes, use of hyperlinked text and pictures). 


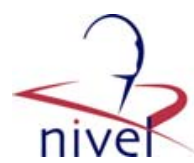

2. The need for two-sided communication, in which there is also room for the emotional aspects of the problems of the patients; counseling in health care seems to be a new focus in PE.

3. The need for clear role definitions and agreement about which health care providers are responsible for which type of information, including the prevention of "boundary fights" and the stimulating role of continuous PE in continuity of care.

4. The empowerment of patient organizations in PE in national health care policy as well as local health care organizations.

5. The need for quality control on PE-issues especially, at the Internet and in other public media.

6. Training in communication skills is a very small part of the medical curriculum as well the education of other professional groups.

7. The need for theoretical and empirical underpinning of the educational models in relationship to the aims of PE, like the processes teaching and counseling. The process of recall and retention, the enhancing compliance, the strengthening of self-regulation, the impact on quality of life.

8. PE has been developed for several specific patient groups (e.g. diabetes, cancer, rheumatism, heart and cardiovascular disease, asthma); their is a need to compare the effects of these strategies in order to increase the effectiveness and to profit from the common experiences.

9. At the start, PE was developed to reduce length of stay in hospitals; now the length of stay reduces the possibilities of PE; more expertise is necessary with PE in polyclinics and day care. Again continuity of education and adequate capacity are a major concern.

10. Finally, it is becoming more obvious that educational effort have their limits. A combination with structural interventions to remove barriers is necessary, but requires to be comprehensive. In a context where waiting lists and a shortage of adequate staff is common, the capacity to apply patient education in keeping with the developing standards may be threatened. Common is the trend to try to delegate these tasks. GP's often put the responsibility on their assistants without providing adequate educational training. At the same time, professionals tend to forget that on the public things said in a hurry without adequate educational care, may have an adverse impact that cannot be corrected by the delegated tasks. Social changes have been said to be more difficult then surgery, but this notion is not yet being reflected in the allocation of resources strategies like healthy hospitals and healthy cities.

\section{REFERENCES}

[1] Bensing JM, Verhaak PFM, van Dulmen AM, Visser APh, editors. Communication: the royal pathway to patientcentered medicine. On communication in health care [special issue], Patient Educ Couns 2000;39:1-145.

[2] Assal JPh, Golay A, Visser APh. New trends in patient education: a trans-cultural and inter-disease approach. Amsterdam: Elsevier, 1995.

[3] Bensing JM. Doctor-patient communication and quality of care. NIVEL, Utrecht, 1991.

[4] Visser APh, editor. Onderzoek naar de tevredenheid van ziekenhuispatienten (Studies on patient satisfaction in hospitals). Lochem/Gent: De Tijdstroom, 1988.

[5] Kanters H. De effectiviteit van patientvoorlichting (Effectivity of patient education). In: Jonkers R, de Haes WFM, Kok GJ, Liedekerken PC, Saan JAM. Effectiviteit van Gezondheidsvoorlichting enopvoeding. Uitgeverij voor Gezondheidsbevordering, Rijswijk, 1988.

[6] Visser APh. Patient education in Dutch hospitals. Patient Educ Couns 1984;6:178-89.

[7] FahrenfortM. Patient education in Dutch hospitals: the fruits of a decade of endeavours. Patient Educ Couns 1990;5:139-50.

[8] Cuisinier MJCJ, van Eijk JThM, Grol R, Jonkers R, Patientenvoorlichting in de eerste lijn (Patient education in primary health care). Care Uitgeverij voor Gezondheidsbevordering, Den Haag, 1989.

[9] Verhaak PFM, van Busschbach JT. Patient education in general practice. Patient Educ Couns 1988;11:119-29.

[10] Eijkman MAJ, Visser AP. Patient envoorlichting en de tandarts (Patient education and the dentist). Utrecht/Antwerpen: Bohn, Scheltema, Holkema, 1987.

[11] Meuwissen JHJM, Postuma HS, de Joode D, Visser AP. Patient education by physicians: a new Dutch approach. Patient Educ Couns 1994;23:69-71.

[12] Maertens H, Maris H. Patientgericht voorlichten: leerboek voor verpleegkundigen (Patientcentered education). No. 1, Landelijk Centrum GVO, Utrecht, 1993.

[13] Damoiseaux V, Visser APh, editors. Patientenvoorlichting: Een interdiciplinaire benadering (Patient education). Assen/ Maastricht: Van Gorcum, 1988. 
Bensing, J.M., Visser, S., Saan, H.

Patient education in The Netherlands.

Patient Education and Counseling: 44, 2001, nr. 1, p. 15-22

[14] Visser APh. Patient education: the Dutch style. Patient Educ Couns 1996;28:79-84.

[15] Jonkers R, de Haes WFM, Kok GJ, Liedekerken PC, Saan JAM. Effectiviteit van

Gezondheidsvoorlichting en-opvoeding (Effectivity of healthpromotion). Uitgeverij voor

Gezondheidsbevordering, Rijswijk, 1988.

[16] Nederlands Huisartsen Genootschap. Als je begrijpt wat ik bedoel . . (If you understand what I mean ... .). Over de voorlichting tijdens het consult. Utrecht, 1999.

[17] Sluijs, EM. Patient education in physical therapy. NIVEL, Utrecht, 1991.

[18] Tijmstra JJ, Bosbom GJ, Bouman K. Experiences of women who decided to continue the pregnancy after the diagnosis of Down's syndrome. Ned Tijdschr Geneeskd 2000; 144(44):2104-7. 